\title{
Advanced glycation end products (AGEs) and their receptor (RAGE) induce apoptosis of periodontal ligament fibroblasts
}

\author{
D.X. Li, T.Z. Deng, J. Lv and J. Ke \\ Department of Stomatology, Air Force General Hospital PLA, Haidian District, Beijing, China
}

\begin{abstract}
Diabetics have an increased prevalence of periodontitis, and diabetes is one of the causative factors of severe periodontitis. Apoptosis is thought to be involved in this pathogenic relationship. The aim of this study was to investigate apoptosis in human periodontal ligament (PDL) fibroblasts induced by advanced glycation end products (AGEs) and their receptor (RAGE). We examined the roles of apoptosis, AGEs, and RAGE during periodontitis in diabetes mellitus using cultured PDL fibroblasts that were treated by AGE-modified bovine serum albumin (AGE-BSA), bovine serum albumin (BSA) alone, or given no treatment (control). Microscopy and real-time quantitative PCR indicated that PDL fibroblasts treated with AGE-BSA were deformed and expressed higher levels of RAGE and caspase 3. Cell viability assays and flow cytometry indicated that AGE-BSA reduced cell viability $(69.80 \pm 5.50 \%, \mathrm{P}<0.01)$ and increased apoptosis $(11.31 \pm 1.73 \%, \mathrm{P}<0.05)$. Hoechst 33258 staining and terminaldeoxynucleotidyl transferase-mediated nick-end labeling revealed that AGE-BSA significantly increased apoptosis of PDL fibroblasts. The results showed that the changes in PDL fibroblasts induced by AGE-BSA may explain how AGE-RAGE participates in and exacerbates periodontium destruction.
\end{abstract}

Key words: RAGE; Apoptosis; Diabetes mellitus; Periodontal diseases

\section{Introduction}

Periodontal disease is a common complication of diabetes (1), but the underlying pathogenesis and internal relationship of the two diseases is not yet clear (2). Previous studies suggest that advanced glycation end products (AGEs) and the receptor for advanced glycation end products (RAGE), which form during chronic hyperglycemia, play roles in the pathogenesis of diverse diseases $(3,4)$, and may also play a key role in periodontitis in the diabetic patient (5).

RAGE was first described in 1992 by Neeper et al. (6), and in 2005, RAGE was identified in gingival tissues of patients with type 2 diabetes (7). Since then, there has been considerable interest in the role RAGE plays in periodontitis. RAGE is a member of the immunoglobulin receptor superfamily and is expressed by diverse cells, including endothelial and smooth muscle cells, lymphocytes, monocytes, and neurons (8). In addition to AGEs, a number of other ligands can bind to RAGE, including amyloid fibrils, amphoterin, and S100/calgranulins. For all tissues so far examined, overexpression of RAGE is associated with accumulation of RAGE ligands. The accumulation of RAGE ligands in diseased tissues leads to sustained receptor expression through positive feedback; this prolongs cell activation and plays a significant role in diverse chronic disorders (9).

The role of AGEs in induction of apoptosis has been extensively investigated, however many of these studies were performed on various cell types, including neuronal and endothelial cells (10-12), and used soluble AGEs, thus resulting in differing apoptotic responses (13-15). Soluble AGEs induce apoptosis through activation of RAGE $(10,12,16)$. This ligand-receptor activation promotes the upregulation of reactive oxygen species (ROS) resulting in apoptosis (17). ROS activate transcription factors to induce the growth arrest and DNA damage 153 (GADD153) gene, which in turn causes the cell to undergo apoptosis through the upregulation of caspase-3 $(18,19)$. At the same time, RAGE binding could also activate multiple signaling pathways such as MAPK, JNKs, or Cdc42/Rac, together with activation of transcription factors $\mathrm{AP}-1$ or $\mathrm{NF}-\kappa \mathrm{B}$ that regulate many important cellular functions (20-22).

The periodontal ligament is a structure connecting teeth to the alveolar bone. It is a key contributor to the process of 
regeneration of the periodontium. Due to the proximity of the periodontal ligament to alveolar bone, cytokine production by PDL fibroblasts might influence the processes of periodontium destruction in periodontal disease. PDL fibroblasts are fibroblast-like cells and are the predominant mesenchymal cells of the periodontal ligament. They are mainly involved in metabolism of the periodontal ligament, synthesis of collagen fibers, and other extracellular matrix components. In addition, PDL fibroblasts produce several proinflammatory mediators and apoptosis factors when stimulated by AGEs.

Taken together, many previous studies indicate a potential relationship of AGEs, RAGE, diabetes, and periodontitis. Although many publications have described the relationship between apoptosis and RAGE in other cell types, no studies have yet examined the role of RAGE in periodontal cellular apoptosis, an important aspect in the pathogenesis of periodontitis. In the present study, we used an AGE-RAGE model comprising cultured human PDL fibroblasts treated with AGE-modified bovine serum albumin (AGE-BSA) (23) to measure the accumulation of AGE-BSA, the apoptosis ratio of AGE-BSA-activated cells, and the expression of RAGE.

\section{Material and Methods}

\section{AGE-BSA preparation}

The AGEs used in the present study were prepared from $50 \mathrm{mg} / \mathrm{mL}$ BSA (Sigma, USA) with $0.5 \mathrm{M}$ glucose (Sigma) in 0.02 M PBS buffer (phosphate buffered saline, Sigma), $\mathrm{pH}$ 7.4. The solution was passed through a $0.22 \mu \mathrm{m}$ filter (Millipore, USA), and incubated in the dark at $37^{\circ} \mathrm{C}$ for 12 weeks. Unmodified BSA (without glucose) was treated identically and used as a control. Following incubation, extensive dialysis against glucose was performed to remove unincorporated glucose. AGEs were identified by fluorescence spectrophotometry (Hitachi V-2001, Japan) (24). The AGE content of our AGE-BSA was $81.8 \mathrm{U} / \mathrm{mg}$ protein, and was $<0.9 \mathrm{U} / \mathrm{mg}$ in the unmodified BSA. The endotoxin content of these preparations was negligible as determined by the limulus amebocyte lysate assay (Endos, USA).

\section{Cell culture}

Human PDL fibroblasts used in the present study were obtained from periodontal ligament tissue harvested from the roots of freshly extracted, uninfected, impacted third molar teeth. Immediately after extraction and under sterile conditions, the teeth were washed in a PBS solution with $200 \mathrm{U} / \mathrm{mL}$ penicillin and $200 \mu \mathrm{g} / \mathrm{mL}$ streptomycin sulfate. Then, the periodontal ligament tissue was gently scraped from the middle third of the root. The tissue was cultured in Dulbecco's Modified Eagle's Medium (Sigma), with $10 \%$ fetal bovine serum (FBS), 2 mM L-glutamine, $100 \mathrm{U} /$ $\mathrm{mL}$ penicillin, and $100 \mu \mathrm{g} / \mathrm{mL}$ streptomycin. Gelatincoated flasks were used for incubation at $37^{\circ} \mathrm{C}$ in a humidified atmosphere (5\% $\mathrm{CO}_{2}, 95 \%$ air). The medium was replaced every 2 days until confluence at 3-5 days. At the third passage, the FBS concentration was reduced to $5 \%$ and the resulting confluent PDL fibroblasts were used for experiments. The research was approved by the appropriate human ethics committee of Air Force General Hospital PLA.

\section{Cell treatment protocol}

PDL fibroblasts were randomly divided into 3 groups: AGE-BSA (group A), BSA (group B), and control (group C). PDL fibroblasts in group $A$ were incubated for $48 \mathrm{~h}$ with AGE-BSA (final concentration of $200 \mu \mathrm{g} / \mathrm{mL}$ ). PDL fibroblasts in group $B$ were incubated for $48 \mathrm{~h}$ with BSA (final concentration of $200 \mu \mathrm{g} / \mathrm{mL}$ ). PDL fibroblasts in group $\mathrm{C}$ were incubated under normal growth conditions. The cells were treated with AGE-BSA or BSA for $48 \mathrm{~h}$ in all experiments except for the cell viability assay (described below), in which viability was assessed continuously in the cells of each group treated with AGE-BSA or BSA for 24,48 , and $72 \mathrm{~h}$. The concentration of AGE-BSA $(200 \mu \mathrm{g} / \mathrm{mL})$ was determined by the results of relevant, published studies (25-27). All experiments were performed 5 times and results are reported as means \pm SE.

\section{Analysis of cell numbers}

For the cell counts, PDL fibroblasts in each group were cultured at $1.0 \times 10^{5} \mathrm{cells} / \mathrm{mL}$ in 24 -well plates, and then observed with an inverted microscope (ECLIPSE TS-100, Nikon, Japan) at $10 \times$ magnification. Photomicrographs were recorded with a digital camera (Nikon). In every well, the software overlaid a grid of evenly spaced horizontal and vertical lines (Adobe Photoshop, version CS3) over the digital image. This allowed cells to be counted on the surface of four quadrants in each well of the culture plate. Using these standardized conditions, counts of PDL fibroblasts were performed by a single examiner who was blinded to the study procedures.

\section{Immunocytochemistry}

Immunocytochemistry was performed using polyclonal monospecific antibodies to RAGE (Becton, Dickinson and Company, USA). Peroxidase-conjugated rat anti-human IgG (Becton, Dickinson and Company) was used to visualize antibody-antigen binding. Briefly, treated cells grown on coverslips were fixed in 95\% alcohol for $15 \mathrm{~min}$, permeabilized with methanol, and blocked with $3 \%$ BSA in PBS for $1 \mathrm{~h}$ at room temperature. Cells were incubated in polyclonal mono-specific antibody to RAGE (1:200 in PBS) overnight at $4^{\circ} \mathrm{C}$. After incubation, the cells were washed with PBS and incubated with rat anti-human IgG for $2 \mathrm{~h}$ at room temperature, washed with PBS, and counterstained with 4'-6-diamidino-2-phenylindole (DAPI; Becton, Dickinson and Company). Expression of RAGE was graded by two investigators as no staining (-), mild 
staining $(+)$, moderate staining $(++)$, and intense staining $(+++)$ (28). After application of biotinylated anti-mouse secondary antibody, sections were counterstained with hematoxylin.

\section{MTT assay}

Cell viability was determined by the methylthiazolyldiphenyl-tetrazolium (MTT) assay, as described previously (29). Briefly, cells were seeded into $200 \mu \mathrm{L}$ culture medium in 96 -well plates at $5 \times 10^{3}$ cells/well. After 24 , 48 , and $72 \mathrm{~h}$ of culture, cells were treated as described in the cell treatment protocol (see above). The cell culture medium was removed, and each well was filled with $100 \mu \mathrm{L}$ fresh DMEM without FBS and incubated for $1 \mathrm{~h}$ at $37^{\circ} \mathrm{C}$. Each well was then incubated with MTT (Sigma) for $4 \mathrm{~h}$, and dimethylsulfoxide (Sigma) was added to dissolve the solid residue. Then, the absorbance at $490 \mathrm{~nm}$ of each well was determined using a microplate reader (Thermo, USA). Viability is reported as a percentage relative to untreated control samples at $24 \mathrm{~h}$.

\section{Detection of apoptosis by flow cytometry}

Apoptosis was assessed by the Annexin V-FITC apoptosis kit (Franklin Lakes, USA) (30), and the cells in each group were harvested at $48 \mathrm{~h}$ for testing. PDL fibroblasts were harvested by trypsin treatment according to the assay manufacturer's instructions, washed twice with cold PBS, and centrifuged (300 g, $5 \mathrm{~min}$ ). Cell pellets were resuspended in $200 \mu \mathrm{L}$ of $1 \times$ binding buffer at $1 \times 10^{6}$ cells $/ \mathrm{mL}$. Then, cells were incubated with $5 \mu \mathrm{L}$ Annexin $\mathrm{V}$ for $10 \mathrm{~min}$ at $4^{\circ} \mathrm{C}$ in the dark, and $5 \mu \mathrm{L}$ propidium iodide $(\mathrm{PI})$ was added for an additional $10 \mathrm{~min}$. Flow cytometry was performed $1 \mathrm{~h}$ later. Data were analyzed using CELLQuest software (Becton, Dickinson and Company). The results were interpreted as follows. Cells in the lower-left quadrant (Annexin $\mathrm{V}^{-} / \mathrm{PI}^{-}$) represented living cells; those in the lower-right quadrant (Annexin $\mathrm{V}^{+} / \mathrm{PI}^{-}$) represented early apoptotic cells; those in the upper-right quadrant (Annexin $\mathrm{V}^{+} / \mathrm{PI}^{+}$) represented late apoptotic cells; those in the upper-left quadrant (Annexin $\mathrm{V}^{-} / \mathrm{PI}^{+}$) represented necrotic cells.

\section{Terminal deoxynucleotidyl transferase dUTP nick end labeling (TUNEL) assay}

For detection of DNA fragmentation by TUNEL staining, cell sections were deparaffinized, rehydrated through a series of graded alcohols, and washed in distilled water followed by PBS. Subsequently, the sections were permeabilized using proteinase $\mathrm{K}(20 \mu \mathrm{g} / \mathrm{mL}, 20 \mathrm{~min}$ at room temperature; Sigma), washed in PBS, incubated in $2 \% \mathrm{H}_{2} \mathrm{O}_{2}$ in $0.1 \mathrm{M}$ PBS for $30 \mathrm{~min}$ at room temperature, and treated with Triton-X (Sigma). The TUNEL reaction was performed using a cell death kit (Becton, Dickinson and Company). Briefly, the sections were incubated with TUNEL reaction mixture for 60 min, washed twice in PBS, treated with converter-POD solution for $30 \mathrm{~min}$, rinsed with
PBS, and visualized by adding 3 '-diaminobenzine for $10 \mathrm{~min}$ at room temperature. They were then washed in PBS, counterstained with hematoxylin, and mounted for light microscopy. Apoptotic cells were identified by their dark brown nuclei under a light microscope.

\section{Hoechst 33258 fluorescent staining}

PDL fibroblasts in each group were washed in ice-cold PBS, and fixed in a solution of methanol-acetic acid $(3: 1, v / v)$ for $15 \mathrm{~min}$ at $4^{\circ} \mathrm{C}$. Apoptotic cells were identified by Hoechst 33258 (5 $\mathrm{gg} / \mathrm{mL}$ in PBS; Sigma) staining for $5 \mathrm{~min}$ at room temperature. The staining of cell nuclei was examined by Olympus fluorescence microscopy (Olympus, Japan) with an excitation wavelength of $340 \mathrm{~nm}$ and an emission wavelength of $460 \mathrm{~nm}$.

\section{Statistical analysis}

Data are reported as means \pm SE and were analyzed using one-way ANOVA for comparisons of group means. For all analyses, differences were considered significant if $P$ was less than 0.05 . All statistical analyses were performed using the SPSS 10.0 software (USA).

\section{Results}

\section{Cell counting, growth, morphology, and RAGE expression}

To determine the extent of RAGE expression after AGE-BSA treatment, human PDL fibroblasts were subjected to AGE-BSA (group A), BSA (group B), or given no treatment (control group $C$ ). There were no significant differences in cell number in the 3 groups after $48 \mathrm{~h}$, which indicated no mass cell mortality had occurred (group A, 215.3 \pm 45.0 cells $/ \mu \mathrm{L}$; group B, 226.6 \pm 55.6 cells $/ \mu \mathrm{L}$; group $\mathrm{C}, 230.5 \pm 50.9$ cells $/ \mu \mathrm{L} ; \mathrm{P}>0.05)$. Figure 1 shows representative photomicrographs of PDL fibroblasts treated with AGE-BSA and BSA for $48 \mathrm{~h}$, and control cells. The control cells and cells treated with BSA had normal fusiform morphology. However, treatment with AGE-BSA caused notable deformation of PDL fibroblasts, and reduced the total number of cells. Figure 1 also shows the expression of RAGE, as detected by immunocytochemistry. Group A exhibited significant immunoreactivity against RAGE, whereas RAGE was basically undetectable in groups $\mathrm{B}$ and $\mathrm{C}$.

\section{Effects of cell viability induced by AGE-BSA}

Figure 2 shows the percentage of viable cells in groups $A$ and $B$ relative to the control group from 24 to $72 \mathrm{~h}$. The cell viability of the control group at $24 \mathrm{~h}$ was deemed as $100 \%$. As time went on, the cell viability of group A was gradually reduced, but almost no change occurred in groups $B$ and C. Comparison of the AGE-BSA and control groups indicated significantly lower cell viability in the AGEBSA group at each time $(P<0.01)$. However, comparison of the BSA group with the control group indicated no 
A

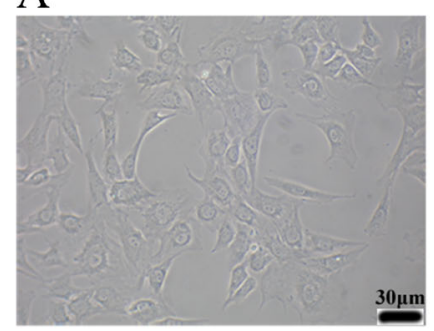

$\mathrm{D}$

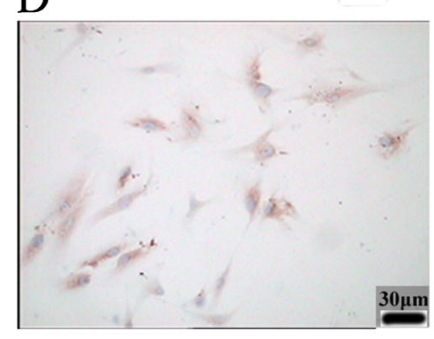

B

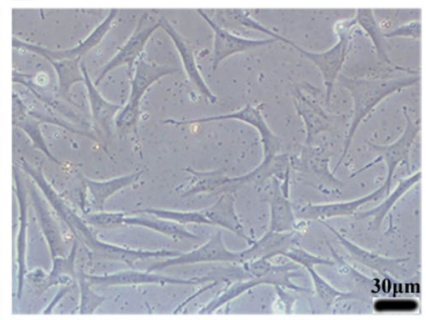

$\mathrm{E}$

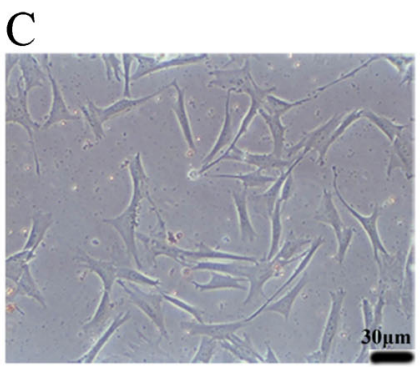

$\mathrm{F}$
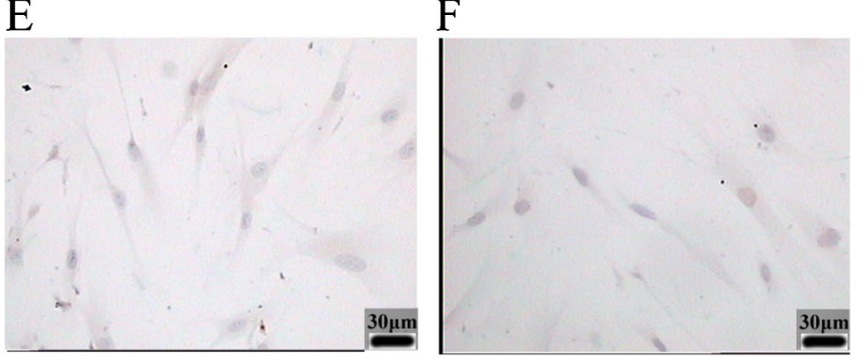

Figure 1. Effect of AGE-BSA on cell morphology and RAGE expression of human periodontal ligament fibroblasts (PDL fibroblasts). Relative to control cells $(C)$, 48-h treatment with AGE-BSA altered cell morphology and reduced the number of cells $(A)$. BSA-treated cells $(B)$ were similar to control cells $(C)$. Similarly, immunocytochemistry indicated that cells treated with AGE-BSA for $48 \mathrm{~h}$ had significantly greater expression of RAGE $(D)$ than BSA-treated cells $(E)$ and control cells $(F)$. Magnification, $400 \times$.

significant differences in cell viability $(\mathrm{P}>0.05)$.

Cell apoptosis measured by flow cytometry, Hoechst 33258 staining, and TUNEL staining

The flow cytometry experiments (Figure 3) indicated that control cells underwent almost no apoptosis or necrosis, with only $1.1 \pm 0.38 \%$ of cells classified as apoptotic. Group B was nearly the same as the control ( $P>0.05$ ), with only $1.5 \pm 0.73 \%$ of cells classified as apoptotic. In contrast, group A had a significantly greater percentage of apoptotic cells $(11.31 \pm 1.73 \%$; $P<0.05)$.

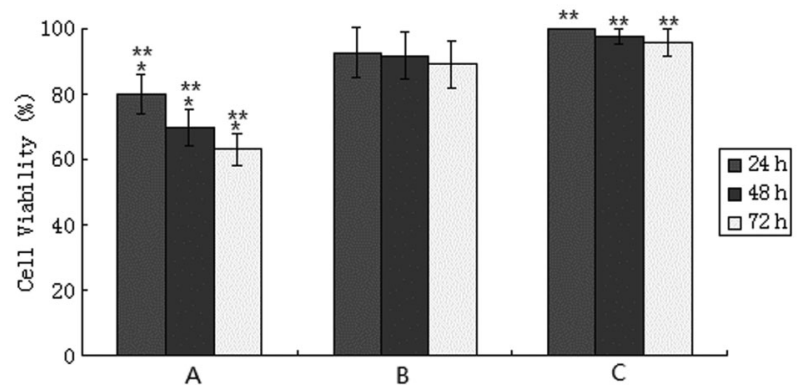

Figure 2. Viability of HPDL fibroblasts treated with AGE-BSA, BSA and control for 24,48 , and $72 \mathrm{~h}$. Pooled analysis indicated significant differences in viability at 24,48 , and $72 \mathrm{~h}$ in group $\mathrm{A}$ $\left({ }^{*} \mathrm{P}<0.05\right)$, and significant differences between group $A$ and group $C\left({ }^{* *} P<0.01\right)$, but no significant difference in the viability of group $B$ and group $C$ at any time $(P>0.05)$. One-way ANOVA was used for statistical analyses.
To further confirm the ability of AGE-BSA to elicit apoptosis in vitro, TUNEL staining was carried out on sections. As illustrated in Figure 4, AGE-BSA treatment caused a significantly higher percentage of TUNELpositive apoptotic cells compared with the other two groups. These results indicated that AGE-BSA is a potent apoptosis-inducing agent in vitro.

The PDL fibroblasts in the control and BSA groups stained with Hoechst 33258, exhibited small, round normal-appearing nuclei. In contrast, cells treated with AGE-BSA showed signs of apoptosis, including highly condensed and fragmented nuclei (Figure 5).

\section{Discussion}

RAGE is expressed in diverse cell types (8) and has been implicated in periodontal complications that accompany diabetes (7). Previous studies of cultured cells have shown that an interaction of AGEs with RAGE modulates certain cellular properties $(31,32)$. In the present study, we hypothesized that RAGE expression is in some way related to PDL apoptosis. Thus, the RAGE pathway appears to be one of the pathogenic mechanisms that connect diabetes and periodontitis.

Injury of PDL fibroblasts induced by the AGE-RAGE system seems to play an important role in the development of advanced stages of diabetes mellitus. The AGERAGE system may cause PDL activation, dysfunction, or death depending on dose and exposure time. Therefore, in this study, AGE-BSA was used to develop a model. Cell 

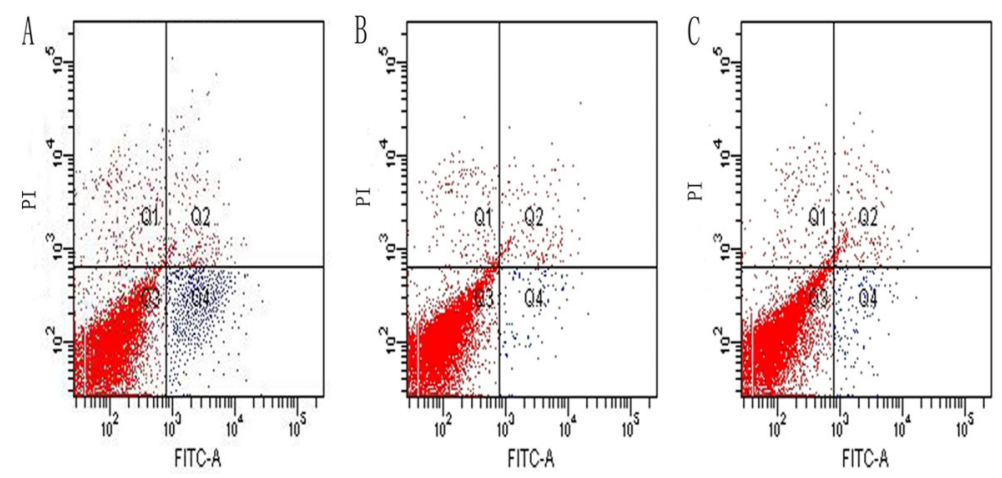

Figure 3. Apoptotic cells can be observed at a specific Q4 of the graphics for groups A, B, and C. Flow cytometry analysis of PDL fibroblasts apoptosis following treatment with AGE-BSA $(A)$ and BSA alone $(B)$. Group A $(11.31 \pm 1.73 \%$ apoptosis) had significantly more apoptotic cells than the control group $(C)(1.1 \pm 0.38 \%$, $\mathrm{P}<0.05)$. The percentage of apoptotic cells in $\mathrm{B}$ $(1.5 \pm 0.73 \%)$ was similar to the control $(\mathrm{P}>0.05)$. All cells were cultured for $48 \mathrm{~h}$ in different culture environments. One-way ANOVA was used for statistical analyses.

counts showed no statistical differences in the 3 study groups, from which it can be concluded that PDL fibroblasts did not die when treated with either AGEBSA or BSA. However, it did not follow from this result that apoptosis had not occurred, since apoptosis occurs prior to cell death. It can be inferred from the study results that PDL fibroblasts treated with AGE-BSA could induce apoptosis. Exposure to AGE-BSA can lead to alteration of cell shape, the recombination of actin filaments, and formation of intercellular gaps. In the present study, we observed that cells treated with AGE-BSA were deformed and contracted, had increased intracellular granular material, and had a roughened profile. Alteration in cell morphology indicates damage to intercellular adhesions and junctions (33). This has implications for cell permeability, because adhesions and junctions of PDL fibroblasts are important for maintaining their function as barriers of the periodontal wall.

The AGE-RAGE interaction modulates cellular properties through the generation of proinflammatory cytokines that participate in cell apoptosis (34). Recent research indicates that apoptosis is a critical step in the destruction of periodontal tissue in diabetic periodontitis (35). For example, in a study of diabetic rats, Liu (35) demonstrated increased apoptosis of bone-lining cells and osteoblasts. Thus, diabetes is associated with a persistent inflammatory response, increased loss of cell attachment, increased alveolar bone resorption, and impaired new bone formation. The latter may be affected by increased apoptosis of bone-lining cells and PDL fibroblasts (35). Alikhani (13) showed that diabetes significantly increases the apoptosis of osteoblast cells in vivo and that this contributes to diabetes-mediated impairment of new bone formation. However, those studies found that apoptosis participated in destruction of periodontal tissue in diabetic patients. Until now, none of the studies fully elucidated the pathway or potential role of apoptosis induced by AGE-RAGE. In this paper, we hypothesized that the high expression of RAGE in cell membranes stimulated by AGE could activate some enzymes or cell factors that could increase the proportion of apoptotic cells. Based on the results of the present study, the AGE-RAGE system may stimulate an increase in apoptosis. The predominant apoptotic pathway involves caspase-8 activation of caspase 3 , and is independent of NF-KB activation (13). Al-Mashat (36) provided direct evidence that increased apoptosis of fibroblasts and osteoblasts caused by diabetes contributes to impaired healing processes, and this can be explained, in part, by diabetes-mediated up-regulation of proapoptotic genes and caspase activity.

This study demonstrated that AGE-BSA increased RAGE expression by PDL fibroblasts. Our immunocytochemistry studies indicated that RAGE expression in AGE-BSA-treated cells, while greater than that of control

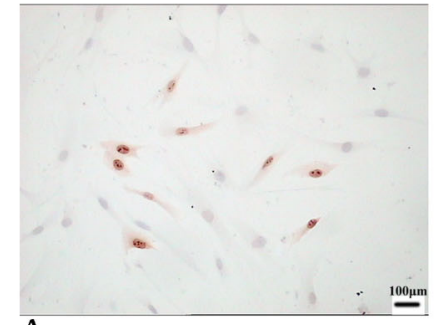

A

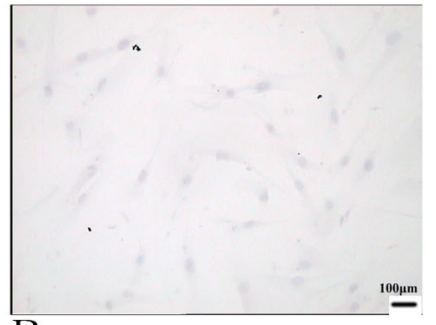

$\mathrm{B}$

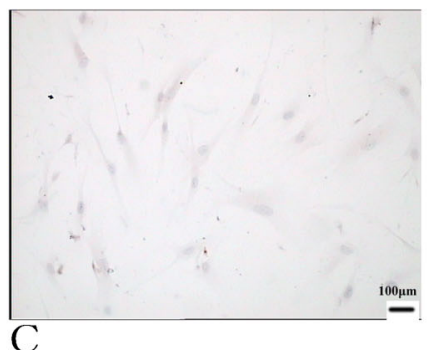

C

Figure 4. Evaluation of apoptosis in cultured PDL fibroblasts using the TUNEL method. Forty-eight hours after culture, apoptosis was detected using an apoptosis detection kit after fixation. Cells with dark brown nuclei were considered apoptotic. The number of apoptotic cells increased in the AGE-BSA group $(A)$ compared with BSA treatment $(B)$ and the control $(C)$. Magnification, $400 \times$. 

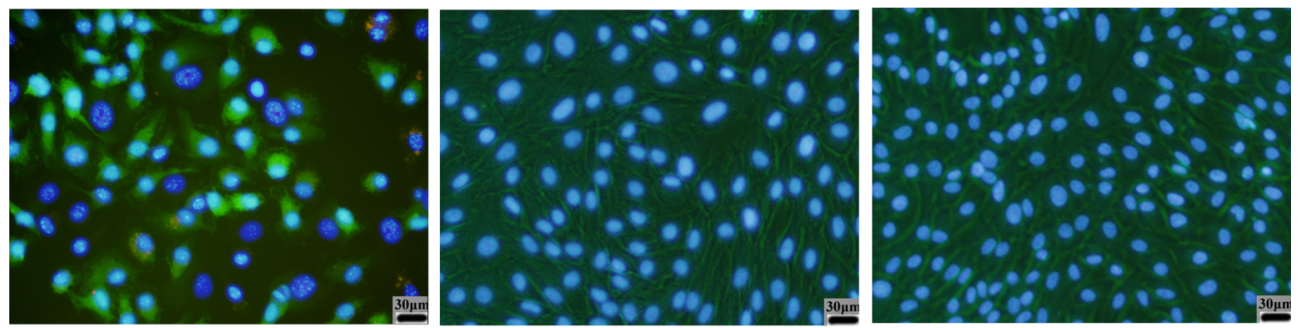

Figure 5. Nuclei were counterstained with Hoechst 33258 and observed under a fluorescence microscope. All cells were cultured for $48 \mathrm{~h}$ in different culture environments. Cells in the AGE-BSA group (left panel) showed bright blue dots in the nuclei, which represented nuclear fragmentation in the apoptotic cells. Cells in the BSA group (middle panel) and control group (right panel) were uniformly blue in viable cells. Magnification, $400 \times$

cells, was still somewhat weak. This could be partially attributable to the brief AGE-BSA stimulus, or because of other unknown biological processes that depleted the amount of RAGE in our cultured cells.

Previously, RAGE had been identified in diverse epithelial cells, including the gingival tissue of diabetic patients (7). RAGE has some biological characteristics that suggest it plays a pivotal role in the pathogenesis of periodontal disease. First, it is a cell receptor associated with proinflammatory responses. Second, increased expression of various receptors is associated with the severity of periodontal disease (37). Apoptosis has been found to be the prominent form of cell death in response to AGE-BSA (14). However, in that study, deficits in wound healing associated with higher rates of fibroblast apoptosis were evaluated. Clinically, apoptosis is preferred over necrosis since it is associated with less severe tissue damage. Apoptosis induced by RAGE appears to be

\section{References}

1. Mealey BL, Rethman MP. Periodontal disease and diabetes mellitus. Bidirectional relationship. Dent Today 2003; 22: 107-113.

2. Taylor GW, Burt BA, Becker MP, Genco RJ, Shlossman M, Knowler WC, et al. Severe periodontitis and risk for poor glycemic control in patients with non-insulin-dependent diabetes mellitus. J Periodontol 1996; 67: 1085-1093, doi: 10.1902/jop.1996.67.10s.1085.

3. Rahbar S. The discovery of glycated hemoglobin: a major event in the study of nonenzymatic chemistry in biological systems. Ann N Y Acad Sci 2005; 1043: 9-19, doi: 10.1196/ annals.1333.002.

4. Amir J, Waite M, Tobler J, Catalfamo DL, Koutouzis T, Katz $\mathrm{J}$, et al. The role of hyperglycemia in mechanisms of exacerbated inflammatory responses within the oral cavity. Cell Immunol 2011; 272: 45-52, doi: 10.1016/j.cellimm. 2011.09.008.

5. Mealey B. Diabetes and periodontal diseases. J Periodontol 1999; 70: 935-949, doi: 10.1902/jop.1999.70.8.935.

6. Neeper M, Schmidt AM, Brett J, Yan SD, Wang F, Pan YC, et al. Cloning and expression of a cell surface receptor for advanced glycosylation end products of proteins. I Biol important in the pathogenesis of a variety of human diseases including Alzheimer's disease, rheumatoid arthritis, cancer, and inflammatory bowel disease, but there have been few reports on periodontitis in diabetes mellitus. In this study, we found that AGE-RAGE causes an increase in apoptosis of critical PDL fibroblasts. As shown in Figures 3, 4, and 5 apoptosis was the main celldeath pathway for cells treated with AGE-BSA for $48 \mathrm{~h}$ at a concentration of $200 \mu \mathrm{g} / \mathrm{mL}$.

In conclusion, the results indicated that in vitro stimulation of PDL fibroblasts by AGE-BSA upregulated RAGE and the accumulation of AGE-RAGE was associated with cell apoptosis, which may contribute to deficient periodontium formation. The findings suggest a possible reason why periodontitis in diabetes mellitus is more serious and refractory than periodontitis in otherwise healthy patients.
Chem 1992; 267: 14998-15004.

7. Katz J, Bhattacharyya I, Farkhondeh-Kish F, Perez FM, Caudle RM, Heft MW. Expression of the receptor of advanced glycation end products in gingival tissues of type 2 diabetes patients with chronic periodontal disease: a study utilizing immunohistochemistry and RT-PCR. J Clin Periodontol 2005; 32: 40-44, doi: 10.1111/j.1600-051X. 2004.00623.x.

8. Schmidt AM, Vianna M, Gerlach M, Brett J, Ryan J, Kao J, et al. Isolation and characterization of two binding proteins for advanced glycosylation end products from bovine lung which are present on the endothelial cell surface. $J$ Biol Chem 1992; 267: 14987-14997.

9. Schmidt AM, Yan SD, Yan SF, Stern DM. The biology of the receptor for advanced glycation end products and its ligands. Biochim Biophys Acta 2000; 1498: 99-111, doi: 10.1016/S0167-4889(00)00087-2.

10. Chen J, Song M, Yu S, Gao P, Yu Y, Wang $H$, et al. Advanced glycation endproducts alter functions and promote apoptosis in endothelial progenitor cells through receptor for advanced glycation endproducts mediate overpression of cell oxidant stress. Mol Cell Biochem 2010; 335: 
137-146, doi: 10.1007/s11010-009-0250-y.

11. Ding Q, Keller JN. Evaluation of rage isoforms, ligands, and signaling in the brain. Biochim Biophys Acta 2005; 1746: 1827, doi: 10.1016/j.bbamcr.2005.08.006.

12. Ramasamy R, Vannucci SJ, Yan SS, Herold K, Yan SF, Schmidt AM. Advanced glycation end products and RAGE: a common thread in aging, diabetes, neurodegeneration, and inflammation. Glycobiology 2005; 15: 16R-28R, doi: 10.1093/glycob/cwi053.

13. Alikhani M, Alikhani Z, Boyd C, MacLellan CM, Raptis M, Liu $\mathrm{R}$, et al. Advanced glycation end products stimulate osteoblast apoptosis via the MAP kinase and cytosolic apoptotic pathways. Bone 2007; 40: 345-353, doi: 10.1016/ j.bone.2006.09.011.

14. Alikhani Z, Alikhani M, Boyd CM, Nagao K, Trackman PC, Graves DT. Advanced glycation end products enhance expression of pro-apoptotic genes and stimulate fibroblast apoptosis through cytoplasmic and mitochondrial pathways. J Biol Chem 2005; 280: 12087-12095, doi: 10.1074/jbc. M406313200.

15. Alikhani M, MacLellan CM, Raptis M, Vora S, Trackman PC, Graves DT. Advanced glycation end products induce apoptosis in fibroblasts through activation of ROS, MAP kinases, and the FOXO1 transcription factor. Am J Physiol Cell Physiol 2007; 292: C850-C856, doi: 10.1152/ajpcell. 00356.2006.

16. Ding Q, Keller JN. Splice variants of the receptor for advanced glycosylation end products (RAGE) in human brain. Neurosci Lett 2005; 373: 67-72, doi: 10.1016/j.neulet. 2004.09.059.

17. Yao D, Brownlee M. Hyperglycemia-induced reactive oxygen species increase expression of the receptor for advanced glycation end products (RAGE) and RAGE ligands. Diabetes 2010; 59: 249-255, doi: 10.2337/db09-0801.

18. Xu C, Bailly-Maitre B, Reed JC. Endoplasmic reticulum stress: cell life and death decisions. J Clin Invest 2005; 115: 2656-2664, doi: 10.1172/JCl26373.

19. Oyadomari S, Mori M. Roles of CHOP/GADD153 in endoplasmic reticulum stress. Cell Death Differ 2004; 11: 381-389, doi: 10.1038/sj.cdd.4401373.

20. Donato R. S100: a multigenic family of calcium-modulated proteins of the EF-hand type with intracellular and extracellular functional roles. Int J Biochem Cell Biol 2001; 33: 637-668, doi: 10.1016/S1357-2725(01)00046-2.

21. Taguchi A, Blood DC, del Toro G, Canet A, Lee DC, Qu W, et al. Blockade of RAGE-amphoterin signalling suppresses tumour growth and metastases. Nature 2000; 405: 354-360, doi: $10.1038 / 35012626$.

22. Huttunen HJ, Fages $\mathrm{C}$, Rauvala $\mathrm{H}$. Receptor for advanced glycation end products (RAGE)-mediated neurite outgrowth and activation of NF-kappaB require the cytoplasmic domain of the receptor but different downstream signaling pathways. J Biol Chem 1999; 274: 19919-19924, doi: 10.1074/jbc.274.28.19919.

23. Murillo J, Wang Y, Xu X, Klebe RJ, Chen Z, Zardeneta G, et al. Advanced glycation of type I collagen and fibronectin modifies periodontal cell behavior. J Periodontol 2008; 79: 2190-2199, doi: 10.1902/jop.2008.080210.

24. Denis U, Lecomte M, Paget C, Ruggiero D, Wiernsperger N, Lagarde M. Advanced glycation end-products induce apoptosis of bovine retinal pericytes in culture: involvement of diacylglycerol/ceramide production and oxidative stress induction. Free Radic Biol Med 2002; 33: 236-247, doi: 10.1016/S0891-5849(02)00879-1.

25. Kim J, Kim CS, Sohn E, Lee YM, Jo K, Kim JS. KIOM-79 protects AGE-induced retinal pericyte apoptosis via inhibition of NF-kappaB activation in vitro and in vivo. PLoS One 2012; 7: e43591, doi: 10.1371/journal.pone.0043591.

26. Shi L, Yu X, Yang H, Wu X. Advanced glycation end products induce human corneal epithelial cells apoptosis through generation of reactive oxygen species and activation of JNK and p38 MAPK pathways. PLoS One 2013; 8: e66781, doi: 10.1371/journal.pone.0066781.

27. Lee JJ, Hsiao CC, Yang IH, Chou MH, Wu CL, Wei YC, et al. High-mobility group box 1 protein is implicated in advanced glycation end products-induced vascular endothelial growth factor A production in the rat retinal ganglion cell line RGC5. Mol Vis 2012; 18: 838-850.

28. Markopoulos AK, Poulopoulos AK, Kayavis I, Papanayotou P. Immunohistochemical detection of insulin-like growth factor-I in the labial salivary glands of patients with Sjogren's syndrome. Oral Dis 2000; 6: 31-34, doi: 10.1111/j.16010825.2000.tb00318.x.

29. Gurgul E, Lortz S, Tiedge M, Jorns A, Lenzen S. Mitochondrial catalase overexpression protects insulinproducing cells against toxicity of reactive oxygen species and proinflammatory cytokines. Diabetes 2004; 53: 22712280, doi: 10.2337/diabetes.53.9.2271.

30. Wang HQ, Quan T, He T, Franke TF, Voorhees JJ, Fisher GJ. Epidermal growth factor receptor-dependent, NFkappaB-independent activation of the phosphatidylinositol 3-kinase/Akt pathway inhibits ultraviolet irradiation-induced caspases- $3,-8$, and -9 in human keratinocytes. J Biol Chem 2003; 278: 45737-45745, doi: 10.1074/jbc.M300574200.

31. Miyata T, Hori O, Zhang J, Yan SD, Ferran L, lida Y, et al. The receptor for advanced glycation end products (RAGE) is a central mediator of the interaction of AGE-beta2microglobulin with human mononuclear phagocytes via an oxidant-sensitive pathway. Implications for the pathogenesis of dialysis-related amyloidosis. J Clin Invest 1996; 98 : 1088-1094, doi: 10.1172/JCl118889.

32. Sakaguchi T, Yan SF, Yan SD, Belov D, Rong LL, Sousa M, et al. Central role of RAGE-dependent neointimal expansion in arterial restenosis. J Clin Invest 2003; 111: 959-972, doi: $10.1172 / \mathrm{JCl} 200317115$.

33. Nordal RA, Wong CS. Molecular targets in radiation-induced blood-brain barrier disruption. Int J Radiat Oncol Biol Phys 2005; 62: 279-287, doi: 10.1016/j.jrobp.2005.01.039.

34. Liang YJ, Jian JH, Liu YC, Juang SJ, Shyu KG, Lai LP, et al. Advanced glycation end products-induced apoptosis attenuated by PPARdelta activation and epigallocatechin gallate through NF-kappaB pathway in human embryonic kidney cells and human mesangial cells. Diabetes Metab Res Rev 2010; 26: 406-416, doi: 10.1002/dmrr.1100.

35. Liu R, Bal HS, Desta T, Krothapalli N, Alyassi M, Luan Q, et al. Diabetes enhances periodontal bone loss through enhanced resorption and diminished bone formation. J Dent Res 2006; 85: 510-514, doi: 10.1177/154405910608500606.

36. Al-Mashat HA, Kandru S, Liu R, Behl Y, Desta T, Graves DT. Diabetes enhances mRNA levels of proapoptotic genes and caspase activity, which contribute to impaired healing. Diabetes 2006; 55: 487-495, doi: 10.2337/diabetes.55. 
02.06.db05-1201.

37. Joe BH, Borke JL, Keskintepe M, Hanes PJ, Mailhot JM, Singh BB. Interleukin-1 beta regulation of adhesion molecules on human gingival and periodontal ligament fibroblasts. $J$ Periodontol 2001; 72: 865-870, doi: 10.1902/jop. 2001.72.7.865. 